\title{
Impact of hard-bottom substrata on the small-scale distribution of fish and decapods in shallow subtidal temperate waters
}

\author{
Stephanie Wehkamp $\cdot$ Philipp Fischer
}

Received: 12 January 2012/Revised: 25 March 2012/Accepted: 3 April 2012/Published online: 18 April 2012

(C) Springer-Verlag and AWI 2012

\begin{abstract}
The micro-scale spatial distribution patterns of a demersal fish and decapod crustacean assemblage were assessed in a hard-bottom kelp environment in the southern North Sea. Using quadrats along line transects, we assessed the in situ fish and crustacean abundance in relation to substratum types (rock, cobbles and large pebbles) and the density of algae. Six fish and four crustacean species were abundant, with Ctenolabrus rupestris clearly dominating the fish community and Galathea squamifera dominating the crustacean community. Differences in the substratum types had an even stronger effect on the micro-scale distribution than the density of the dominating algae species. Kelp had a negative effect on the fish abundances, with significantly lower average densities in kelp beds compared with adjacent open areas. Averaged over all of the substrata, the most attractive substratum for the fish was large pebbles. In contrast, crustaceans did not show a specific substratum affinity. The results clearly indicate that, similar to other complex systems, significant micro-scale specieshabitat associations occur in northern hard-bottom environments. However, because of the frequently harsh environmental conditions, these habitats are mainly sampled from ships with sampling gear, and the resulting data cannot be used to resolve small-scale species-habitat associations. A detailed substratum classification and community assessment, often only possible using SCUBA diving, is therefore important to reach a better understanding
\end{abstract}

Communicated by Heinz-Dieter Franke.

S. Wehkamp $(\varangle) \cdot$ P. Fischer

Biologische Anstalt Helgoland, Center for Scientific Diving,

Alfred Wegener Institute for Polar and Marine Research,

Kurpromenade 207, 27498 Helgoland, Germany

e-mail: stephanie.wehkamp@awi.de of the functional relationships between species and their environment in northern temperate waters, knowledge that is very important with respect to the increasing environmental pressure caused by global climate change.

Keywords Micro-scale $\cdot$ Substratum $\cdot$ North Sea Chryptobenthic $\cdot$ Sublittoral $\cdot$ SCUBA $\cdot$ Kelp

\section{Introduction}

It is well known that substratum characteristics play an important role in the temporal and spatial distribution of benthic and demersal fish (Gotceitas et al. 1995; Fraser et al. 1996; Fischer and Eckmann 1997a, b; Anderson and Millar 2004; Stal et al. 2007; Damalas et al. 2010) and crustacean species (Simoes et al. 2001; Jackson et al. 2006; Pallas et al. 2006). Species-habitat interactions affect communities on a large-scale (among habitats including sandy flats, rocky shores or seagrass beds) but also within small-scale microhabitat ranges (e.g. within a specific reef structure or stone formation; Gotceitas et al. 1995; Fraser et al. 1996; Jackson et al. 2006; Pallas et al. 2006; Scharf et al. 2006), and some processes can only act at small scales and other only at large scales (Underwood and Chapman 1996). To understand why a certain species does or does not settle in a certain area at a certain time, it is crucial to unravel the associations between the individual species and the detailed habitat parameters to elucidate which habitat features are relevant for a positive settlement decision of the individual species (Robinson and Tully 2000; Pardo et al. 2007; Moore et al. 2010). A basic problem in the assessment of such functional relationships on microhabitat scales, however, is the often overly large 
scale of the sampling units (Garcia-Charton and Ruzafa 1998; Fischer et al. 2007; Sayer and Poonian 2007), especially in studies using classical time- or space-integrative methods, such as dredges or fyke nets. Using these methods, a characterisation of substratum types is often completed only on a very broad range, such as Posidonia beds, rocky or sandy bottom or artificial habitats (Stal et al. 2007; Hunter and Sayer 2009; La Mesa et al. 2011).

Several studies, however, have proven that even within areas commonly characterised as uniform habitats, fish and macro-crustaceans are not distributed at random but rather strictly following the micro-scale occurrences of specific habitat patterns that occur at scales sometimes even smaller than the organisms themselves (Gotceitas et al. 1995; Fraser et al. 1996; La Mesa et al. 2006; Chatfield et al. 2010). Chatfield et al. (2010) recently hypothesised that for a thorough explanation of fish distributions and a deeper functional understanding of why certain fish species are found where they are, a much finer substratum classification is necessary than that normally produced in field studies.

Most of the studies with a sufficient spatial resolution have been conducted on species associations in warm or temperate areas and on suprabenthic fish species (Anderson and Millar 2004; Morton and Gladstone 2011). In contrast, only few researchers have studied the fish-habitat relationships of sublittoral cryptobenthic fish assemblages in northern boreal rocky, hard-bottom systems (La Mesa et al. 2006), although this type of substratum forms a main part of the substratum of many northern coasts. Most of the fish communities of these habitats contain a large fraction of cryptobenthic fish, which are small and spend most of their time closely associated with the bottom substrate. Because these small fish are often highly vulnerable to predation by larger fish, the cryptobenthic species are typically heavily camouflaged and often dwell in complex, hard-bottom structures that are proportional to their own body size. For these species, the depth and bottom slope, for example, can be considered as macro-scale habitat features, while relevant micro-scale substratum characteristics may include the proportion of the substratum with larger stones or the complexity and heterogeneity of a rocky substratum itself (La Mesa et al. 2006). Robinson and Tully (2000) stated the same finding for macro-crustacean species. These authors found that variations in the physical complexity of the substratum and other habitat characteristics significantly affect the small-scale spatial distribution of decapod species and the decapod age structure in a certain area. Pallas et al. (2006) even suggest that the variability in spatial patterns of decapod crustaceans on rocky bottoms is primarily related to substratum type and geographical location. However, most of these studies have considered invertebrate communities in the more-accessible intertidal area or have investigated sessile and less-mobile organisms (Fraschetti et al. 2005; Reicherti et al. 2008), and only few studies have dealt with the subtidal community in northern areas to date.

In this study, we therefore focussed on the temporal and spatial distribution patterns of the sublittoral demersal fish and decapod macro-crustacean community in a northern hard-bottom system of Helgoland in the southern North Sea $\left(54^{\circ} 11^{\prime} \mathrm{N}, 07^{\circ} 52^{\prime} \mathrm{E}\right)$. The island Helgoland is well known for its complex hard-bottom substratum characteristics and extensive sublittoral kelp forests (De Kluijver 1989). A systematic study of the sublittoral fish community around Helgoland was completed by Krüß (1988), who investigated the biology of the common benthic fish species at different sampling stations. He discussed the spatial distribution of different fish species with respect to substratum types and proposed that some of the species showed significant preferences for specific habitat characteristics. De Kluijver (1991) and Reicherti et al. (2008) investigated the spatial patterns of the sublittoral and intertidal benthic community around Helgoland but focussed on sessile organisms. Unfortunately, only a few of these studies (De Kluijver 1991; Harms 1993) included the mobile macro-fauna, and none of the researchers analysed the species-substratum associations of vagile organisms on a quantitative level.

To address this lack of knowledge regarding the mobile macro-fauna of one of the most important nature reserve areas in the southern North Sea, we examined the microspatial distribution patterns of fish and crustacean species with respect to substratum characteristics.

The study was conducted at a typical sublittoral kelp site in approximately $5 \mathrm{~m}$ of water depth. The species were counted along line transects, and the substratum was classified into three different types (rock, cobbles and large pebbles). Using these data, we tested the null hypothesis that the fish and macro-crustacean species in the area are distributed independently on a particular hard-bottom substratum type.

\section{Materials and methods}

\section{Study site}

Helgoland island is located in the southern North Sea (German Bight) at $54^{\circ} 11^{\prime} \mathrm{N}$ and $7^{\circ} 55^{\prime} \mathrm{E}$, approximately $50 \mathrm{~km}$ off the German coastline. The island is the tip of a $35-\mathrm{km}^{2}$ subtidal rock formation located in the southern part of the soft-bottom-dominated North Sea. This sedimentological particularity has led to a geologically and ecologically isolation from similar hard-bottom areas, the closest of which occur in Norway and Britain (Franke and Gutow 2004). 
Since 1981, about 5.138 ha of the rocky area around Helgoland, the "Helgoländer Felssockel", has been classified as a nature reserve through the federal state SchleswigHolstein. The influence through fishing activity is limited because fishing is allowed only for professional Helgoland fishermen with standing gear like weirs or pots but no trawling or gill-netting is allowed. Fisheries' activity in general is limited to catches of lobster and edible crabs for the gastronomy, whereas catch rates for the endangered lobster (Homarus gammarus) are given.

The dominating types of substrata around Helgoland are red sandstone and limestone (De Kluijver 1991). Additionally-especially in the deeper northeasterly directionfields of pebbles (debris of red sandstone, chalkstone and rock) exist. During the summer, a considerable portion of the sublittoral region to approximately $4 \mathrm{~m}$ of depth is dominated by dense growth of brown algae (Laminaria hyperborea), with single individuals reaching depths down to $8 \mathrm{~m}$ (Lüning 1970). The study site was located to the north of the island, approximately $400 \mathrm{~m}$ away from the coastline. In about 5-m water depth by mean low-water spring (MLWS) after hydrographic chart, three experimental sites were established parallel to the shoreline (Fig. 1). The seabed of the study area is almost flat with a slight increase in the depth in the northeasterly direction and a slight decrease in the southwesterly direction towards the coastline. The average local tidal range is about $2.5 \mathrm{~m}$. During the study time, the lowest tidal range was $2.18 \mathrm{~m}$ in June and the highest tidal range was reached with $3.01 \mathrm{~m}$ in September.

\section{Survey methods}

\section{Fish and crustaceans}

This study was set within the frame of a major project with specific guidelines for the experimental design. To ensure high safety for the divers and enough time under water for a solid data sampling, we decided to fix the line transects. The position of each counting station was marked on the transect lines. Possible risks for divers can exist through strong tide currents or bad visibility especially after storm events.

At each site, three 20-m-long line transects were sampled from June to September 2009 on a monthly basis using SCUBA-supported line-transect counting (Fig. 1). Sampling was conducted at $0,5,10,15$ and $20 \mathrm{~m}$ along each line transect. At each of the station, two square metres were sampled within a virtual square-metre quadrat to the left and another square-metre quadrat to the right of the transect line.

Unfortunately, the diver could not finish the counting at some occasions because of extremely bad visibility or swell-induced seasickness under water, and we missed a total of $32 \mathrm{~m}^{2}$ so that a total of only $328 \mathrm{~m}^{2}$ were available at the end of the study instead of possible $360 \mathrm{~m}^{2}$.

To determine the quadrat size under water, the diver used a 1-m-long PVC pipe. Approaching the counting station, the diver began by counting the fish above the substrate up to eye level and then, when positioned in front of the counting area, counting the benthic species. In a last step, the stones measuring up to $10 \mathrm{~cm}$ were turned carefully to look for hidden organisms (Beldade and Goncalves 2007). Because the area is subject to severe and frequent storm events with significant substratum disturbance also of larger stones and cobbles on a regular basis, this procedure can be assumed as a comparatively minor impact and disturbance to the species compared to normal disturbances because of weather conditions.

To standardise the counting and to eliminate the differences in the sampling technique, the same diver made the observations throughout the survey period (Sayer et al. 1993; Magill and Sayer 2002). All of the samplings were conducted between 10 a.m. and 2 p.m. to reduce the possible effects of diel activity. The field campaigns were conducted between the 14th and 30th of June, the 15th and 21 st of July, the 3rd and 8th of August and the 8th and 18th of September 2009.

\section{Substratum classification}

Following the dieback of $L$. hyperborea in October, we assessed the natural bare substratum in the counting quadrats along the line transects. A photo frame of $50 \times 50 \mathrm{~cm}$ was placed at each counting station randomly, and 16 photographs $(12.5 \times 12.5 \mathrm{~cm})$ of the substratum were taken with a digital camera (Olympus $\mu 1030$ SW waterproof). Based on the Udden-Wentworth grain-size scale (Wentworth 1922), the substratum of each photograph was classified by four independent observers into one of the three substratum categories-rock (smooth rock with few irregularities, sometimes covered with sand or fine gravel), cobbles (rock with cobbles of approximately 65-250 $\mathrm{mm}$ ) and large pebbles (pebbles between approximately $15-65 \mathrm{~mm}$ in between fine gravel; Fig. 2)depending on the dominant substratum category found in the $12.5 \times 12.5 \mathrm{~cm}$ square. The predominant substratum type of each station was defined by using the modal value of the 16 substrata determinations within the photo frame.

\section{Algae}

In addition to the substratum types, we analysed the algal growth along the line transects for each counting station 


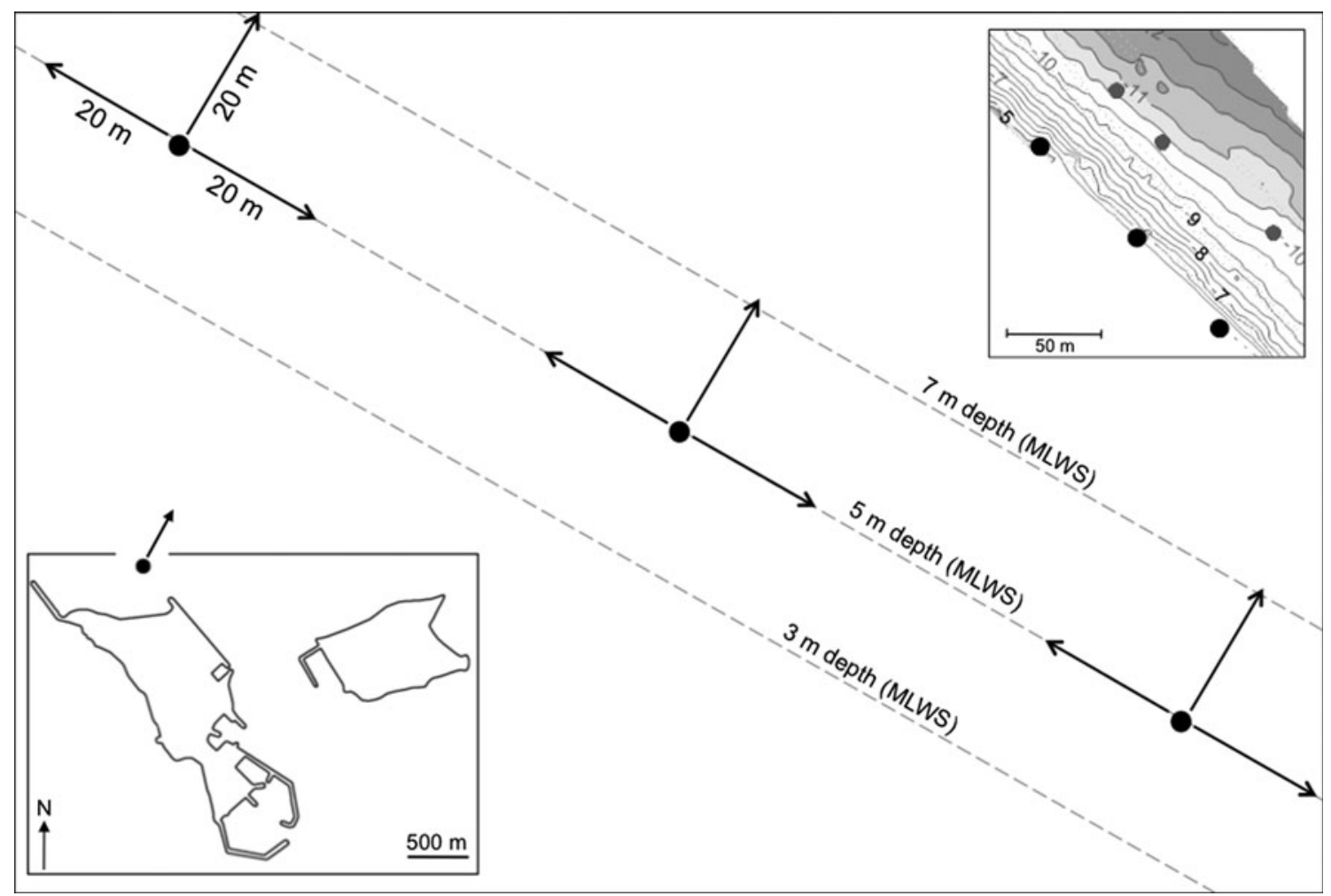

Fig. 1 The study area, approximately $400 \mathrm{~m}$ north of Helgoland's coastline. At each of the three sites, in 5-m water depth by mean lowwater spring (MLWS), the sampling was performed through SCUBA diving on a monthly basis using quadrats $(1 \times 1 \mathrm{~m})$ along three 20-m-long transect lines. Depth data provided by Klaus Ricklefs (FTZ, Kiel)
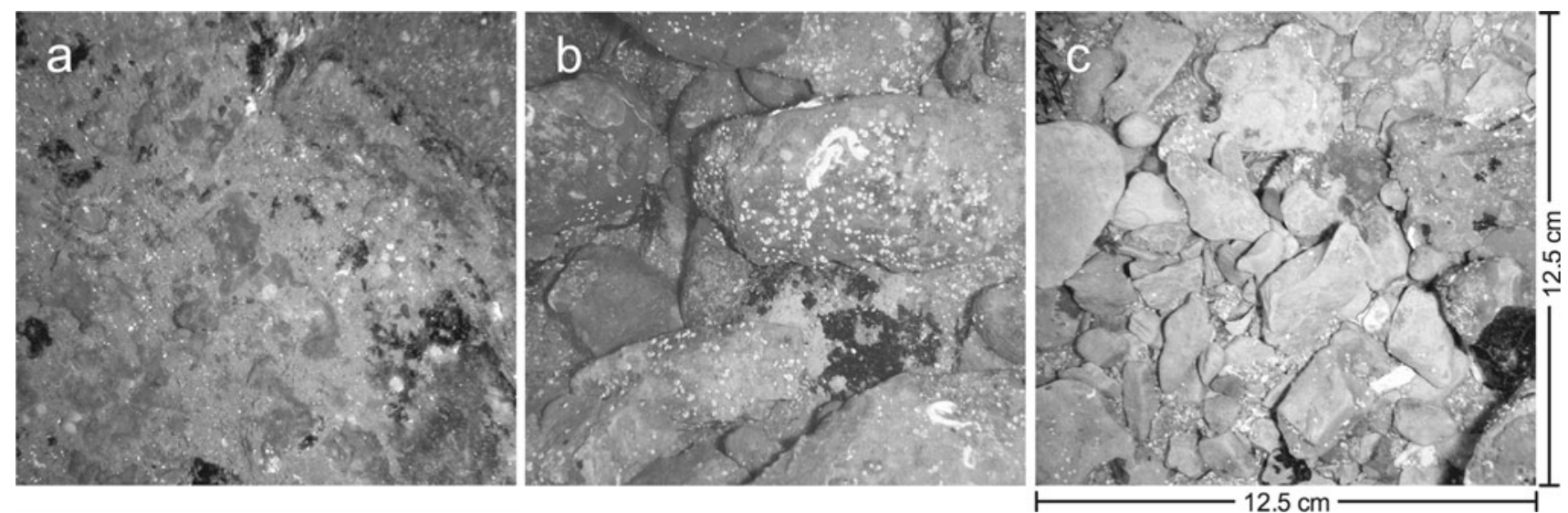

Fig. 2 The three substratum categories in the study area. a Rock (smooth rock with few irregularities, sometimes covered with sand or fine gravel), b cobbles (rock with cobbles between approximately

and the corresponding substrata characteristics. The density of Laminaria and red algae was calculated for every month. For the brown algae L. hyperborea, the stipe density was determined on an ordinal level. We classified a density of 20-50 Laminaria $\mathrm{m}^{-2}$ as "dense", 5-20 Laminaria $\mathrm{m}^{-2}$ as "present" and $<5$ Laminaria $\mathrm{m}^{-2}$ as "sparse". Additionally, the coverage by bushy or branched red algae, such as Delesseria sanguinea, Membranoptera alata,
65-250 mm), c large pebbles (pebbles between approximately $15-65 \mathrm{~mm}$, in between fine gravel)

Cystoclonium purpureum, Plocamium cartilagineum and species of the genus Polysiphonia, was classified as station) or "absent" (no or only sparse algal growth). No further discrimination among different species was made. For the different substratum types, we calculated which algal density occurred mainly at each sampling station (Table 1). "present" (dense growth, covering over $50 \%$ of a counting 
Table 1 Density of Laminaria hyperborea (left side of the table) over the study time: ++ stands for dense, with $20-50$ Laminaria $^{-2}$; + stands for present, with 5-20 Laminaria $\mathrm{m}^{-2}$; and 0 stands for sparse, with only 0-5 Laminaria $\mathrm{m}^{-2}$

\begin{tabular}{lllllll}
\hline $\begin{array}{l}\text { Laminaria } \\
\text { hyperborea }\end{array}$ & Rock & Cobbles & $\begin{array}{l}\text { Large } \\
\text { pebbles }\end{array}$ & Red algae & Rock & $\begin{array}{l}\text { Cobbles } \\
\text { pebbles }\end{array}$ \\
\hline June & ++ & ++ & 0 & June & + & + \\
July & ++ & ++ & 0 & July & + & + \\
Aug & ++ & ++ & 0 & Aug & + & + \\
Sept & 0 & 0 & 0 & Sept & + & 0 \\
\hline
\end{tabular}

The growth of bushy or branched red algae (right side of the table) over the study time was reported as + for present (dense growth, covering a main part of the substratum) and 0 for absent (no or only sparse algal growth)

\section{Abiotic factors}

The water temperature was measured continuously at the "Kabeltonne" site $\left(54^{\circ} 11.3^{\prime} \mathrm{N}, 7^{\circ} 54.0^{\prime} \mathrm{E}\right)$ within the frame of the Helgoland Roads time series (Wiltshire et al. 2008, 2010) nearby the study side. We calculated the average temperatures for the sampling period for each month using the mean value of all sampling days in the specific month. To quantify the transparency of the water in metres during the transect counting, a Secchi disc was fixed at the starting position of the southern-most transect in the horizontal direction, and the horizontal Secchi distance was measured by the diver. The observations were completed only when the horizontal Secchi distance was at least $1 \mathrm{~m}$. Furthermore, the dive time, tides and special observations were recorded during each sampling.

Data analysis

All of the visible benthic and suprabenthic fish and decapod crustaceans were identified to the species level if possible. We determined benthic gobies as Pomatoschistus minutus. This classification was made because catch data of benthic gobies around Helgoland (Hielscher 2012, pers. comm.) indicate that the majority of the gobies in this area belong to this species. Because the species identification of gobies in the field is almost impossible, we accepted the risk that some Pomatoschistus microps, especially smaller individuals, were included accidentally.

\section{Statistical analyses}

To first discriminate the seasonal and substratum effects on the overall abundances of the fish and crustaceans, a two-way ANOVA mixed model for repeated measures (month) based on the number of fish $\mathrm{m}^{-2}$ was applied, with a subsequent Bonferroni-corrected post hoc test. The homogeneity of variance of the data was tested using the Bartlett test.

To detect a possible impact of the algal density on the fish and crustacean abundances over the months and as well over the substratum types, an ANCOVA was applied, whereas the algal density was used as covariable.

For a detailed analysis of the effects of the different substratum types on the fish and crustacean abundances, the absolute abundance data-individual number per square metre (ind. $\mathrm{m}^{-2}$ )—were converted into a percentage of occurrences per substratum type. For this calculation, all of the fish that were counted in a single month (e.g. July) were summed up and were taken as $100 \%$. Then, the percentage of the occurrence of each species in each of the types of substratum was calculated for each month separately. The effects of the different substrata on the fish and crustacean occurrence were then tested using the nonparametric Friedman test procedure, with a subsequent nonparametric Nemenyi post hoc test. All of the statistical analyses were performed using a significance level of $\alpha=0.05$.

The effects of the different substratum types on the individual species were analysed in detail. For this calculation, we also used the distribution (as a percentage) of the individual fish and crustacean species among the three substratum categories separately for each month. This analysis was conducted for the six most abundant fish species (the species with a total count of more than 20 over the season) and for the four most abundant crustacean species (the species with a total count of more than 100 over the season).

\section{Results}

Water temperature

The average on-site water temperature during the sampling period showed a typical bell-shaped curve, with a mean value of $14.03{ }^{\circ} \mathrm{C}$ (SD 1.4) over the sampling days in June, $16.70{ }^{\circ} \mathrm{C}$ (SD 0.2) in July, a maximal value of $18.05{ }^{\circ} \mathrm{C}$ (SD 0.4) in August and slightly lower values of $17.43{ }^{\circ} \mathrm{C}$ (SD 0.4) in September (Fig. 3). 
Fig. 3 The average temperature in ${ }^{\circ} \mathrm{C}$ (right, $y$-axis) over the sampled days in the studied months and the fish (a) and crustacean (b) abundances $\mathrm{m}^{-2}$ (mean and SD) over the sampling period in the three substrate categories, rock, cobbles and large pebbles
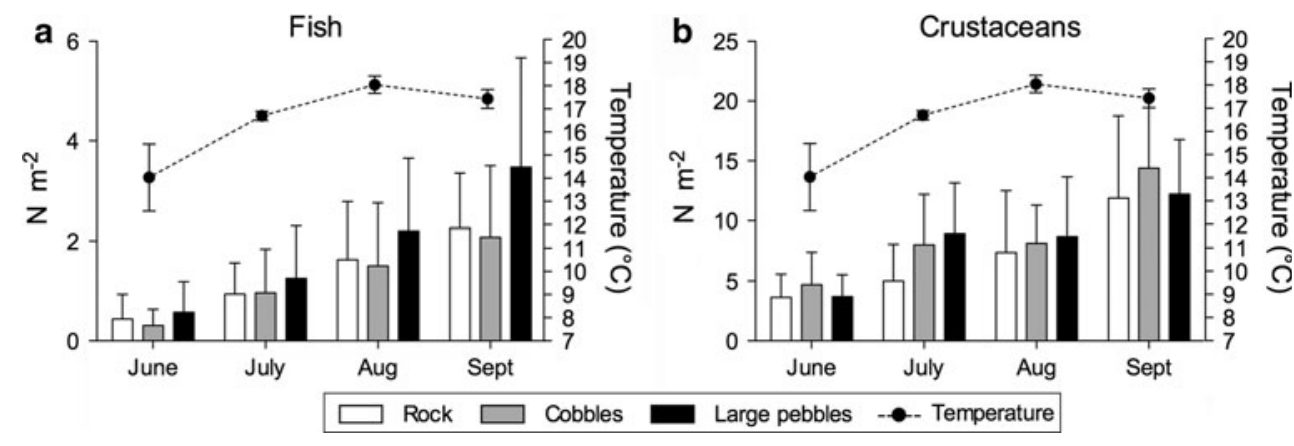

Substratum types and algae

\section{Substratum type}

Of the 41 sampling stations, eight were classified as substratum type rock, 13 stations as cobbles and 20 stations as large pebbles. All substratum types were found at each site and every transect direction, whereas the category large pebbles was predominant in the northeasterly direction.

\section{Laminaria hyperborea}

A dense (20-50 $\mathrm{m}^{-2}$ ) substratum coverage of large kelp (mainly L. hyperborea) was observed in June, July and August in the categories cobbles and rock (Table 1). The growth of kelp in the area was generally closely associated with these two substratum categories, and no or only few kelp plants were found on the substratum category large pebbles at any time (Table 1). In September, the kelp died back in the entire area, dropping quickly to a level of only few to no plants $\mathrm{m}^{-2}$.

In terms of structural complexity, L. hyperborea reached its maximum stipe length $(>50 \mathrm{~cm})$ in June to August, with an overall height of the entire plant of approximately 2-3 m. In June and July, the leaves were broad and without fouling, and the stipes had a diameter up to $3 \mathrm{~cm}$ with complex and broad holdfasts. In September, the older plants began to collapse, and only the multiannual holdfasts, sometimes with the stipes, remained; thus, the structural complexity of the kelp habitat significantly decreased.

Over the months, the Laminaria density showed no significant effect on the fish (ANCOVA, $F=2.669$, $d f=2, p=0.0725$ ) or crustacean abundances (ANCOVA, $F=0.73, d f=2, p=0.484)$. Because the substratum types influenced the fish abundances significantly, we analysed a possible impact of the Laminaria density over the different substratum types. The density of Laminaria is negatively correlated with the fish abundance (ANCOVA, $F=4.898, d f=2, p=0.0086$ ), and the substratum large pebbles with the lowest density of Laminaria contained the most fish.
Red algae

Following the same pattern as the kelp, a dense growth of bushy or branched red algae was observed on the rocky and cobble substratum in June to August, while no or sparse growth was found in the substratum large pebbles (Table 1). In contrast to the kelp pattern, red algae plants remained present in September on the category rock, whereas in the areas with cobbles and large pebbles, only sparse or no red algae were found.

The density of red algae had no significant effect on the fish (ANCOVA, $F=0.287, d f=1, p=0.593$ ) and crustacean (ANCOVA, $F=0.294, d f=1, p=0.589$ ) abundances over the months. Furthermore, no effect of red algae was observed over the substratum types on fish abundances (ANCOVA, $F=0.577, d f=1, p=0.4487$ ).

Fish and crustacean abundance

A total of 510 fish and 2,708 macro-crustaceans were counted over the entire sampling period. With a total of 328 quadrats $(1 \times 1 \mathrm{~m})$ analysed, a mean fish density of 1.55 ind. $\mathrm{m}^{-2}$ (SD 1.0) and a mean crab density of 8.26 ind. $\mathrm{m}^{-2}$ (SD 3.6) were calculated and averaged throughout the entire study.

When analysing the temporal (month) and spatial (substratum categories) effects in detail, a significant increase in the fish and crustacean abundance was observed over the months, with the highest average values of 2.79 (SD 1.9) fish $\mathrm{m}^{-2}$ (ANOVA, $F=19.83, \quad d f=3$, $p<0.0001)$ and 12.84 (SD 5.5) crustaceans $\mathrm{m}^{-2}$ (ANOVA, $F=42.57, d f=3, p<0.0001$ ) in September, over all of the substrate categories.

The fish were significantly more abundant in the large pebbles substratum to cobbles and rock (Fig. 3a, ANOVA, $F=5.41, d f=2, p=0.008)$, and this effect was most prominent in September (Bonferroni post hoc test: $p<0.01$, Fig. 3a). Summarised over all of the months, the large pebbles region contained $42.3 \%$ (SD 2.2) of the total fish abundance and therefore significantly more fish (Nemenyi post hoc test, $k=2, p=0.05$ ) than the cobble substratum (27.2\%, SD 3.0). In terms of the fish 
abundance, the rocky substratum $(30.5 \%$, SD 1.8) contained intermediate values and did not significantly differ from either of the other substratum types (Fig. 4a).

In contrast, for the overall crustacean abundance, no significant substratum effect could be found (Fig. 3b, ANOVA, $F=0.93, d f=2, p=0.4015)$. The highest percentages of crustaceans were counted in the category cobbles (36.64 \%, SD 2.3), followed by large pebbles (34.82 \%, SD 4.6) and rock (28.54\%, SD 3.9; Fig. 4b).

Species-specific distribution

\section{Ctenolabrus rupestris}

The goldsinny ( $C$. rupestris) was the most abundant fish species in the area, with an average abundance of 0.5 ind. $\mathrm{m}^{-2}$ (SD 0.2). The goldsinnies were almost equally distributed throughout all of the three substratum categories, with 37,33 and $30 \%$ of their occurrence in the categories rock, cobbles and large pebbles, respectively (Fig. 5a). Most of the goldsinnies were counted in August and September, followed by July and June (Fig. 6a).

\section{Pholis gunnellus}

With an average abundance of only 0.24 ind. $\mathrm{m}^{-2}(0.1 \mathrm{SD})$, benthic gunnels ( $P$. gunnellus) were clearly less abundant than goldsinnies, even though gunnels were the second most abundant species in the sampling area. Contrary to the suprabenthic goldsinny, $P$. gunnelus showed a distinct substratum affinity, with $50 \%$ of the total number of sightings in large pebbles and only 31 and $22 \%$ of the gunnels found in the substratum categories cobbles and rock (Fig. 5a). The high appearance in large pebbles was present in all of the months except June (Fig. 6a).

\section{Taurulus bubalis}

The long-spined sea scorpion (T. bubalis) was found in all of the substratum categories (Fig. 6a), with an average density of 0.19 ind. $\mathrm{m}^{-2}$ (SD 0.1), but was mostly found in the substratum large pebbles ( $44 \%$ of the total number of sightings). Only $29 \%$ of the fish were observed on the rocky substratum, and $27 \%$ were found on the cobble substratum (Fig. 5a). However, both the substratum associations and the abundances of $T$. bubalis strongly varied among the months (Fig. 6a).

\section{Pomatoschistus minutus}

The sand goby (P. minutus; 0.19 ind. $\mathrm{m}^{-2}, \mathrm{SD} 0.2$ ) was almost as abundant as the long-spined sea scorpion, and $P$. minutus was observed mainly in the substratum large pebbles (Fig. 5a). A total of $72 \%$ of the sand gobies was observed in this substratum type, while only $17 \%$ of the total number of this species was found in rocky habitats and $11 \%$ was found in cobbles (Fig. 5a). P. minutus revealed a distinct seasonality, with no or only rare specimen observations in June and July and significantly higher mean abundances in August and September (Fig. 6a).

\section{Callionymus lyra}

We found only females or immature males of $C$. lyra (Wheeler 1978), with an average size of approximately $8-10 \mathrm{~cm}$ and a density of 0.17 ind. $\mathrm{m}^{-2}$ (SD 0.2; Fig. 5a). The dragonet was equally found in the substrata large pebbles $(48 \%)$ and rock (41\%) but only $11 \%$ occurred in the substratum type cobbles (Fig. 5a). The dragonets showed the strongest seasonality during the sampling period; virtually, the only times dragonets were observed was in August and September (Fig. 6a).

\section{Gobiusculus flavescens}

The two-spotted goby (G. flavescens) was mainly present in September (Fig. 6a). During September, the gobies occurred with an average abundance of 0.15 ind. $\mathrm{m}^{-2}$ (SD 0.2 ) and were mainly distributed in the substrata cobbles (49\%) and large pebbles (47\%) but were only sparse in rocky areas (4\%; Fig. 5a).
Fig. 4 The distribution of the fish (a) and crustaceans (b) per month among the three substratum categories. The presence of different letters above the bars indicates significant differences among the substratum categories
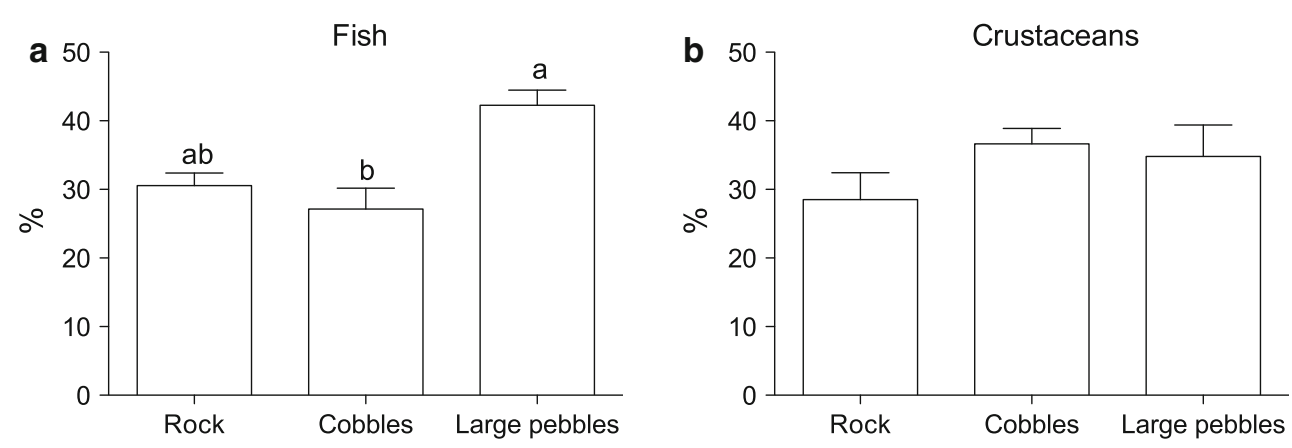
Fig. 5 Relative distributions of the six most abundant fish species (a) and the four most abundant crustacean species (b) with respect to the three substratum categories, rock, cobbles and large pebbles. The numbers above the bars represent the absolute counts of the different species over the sampling period

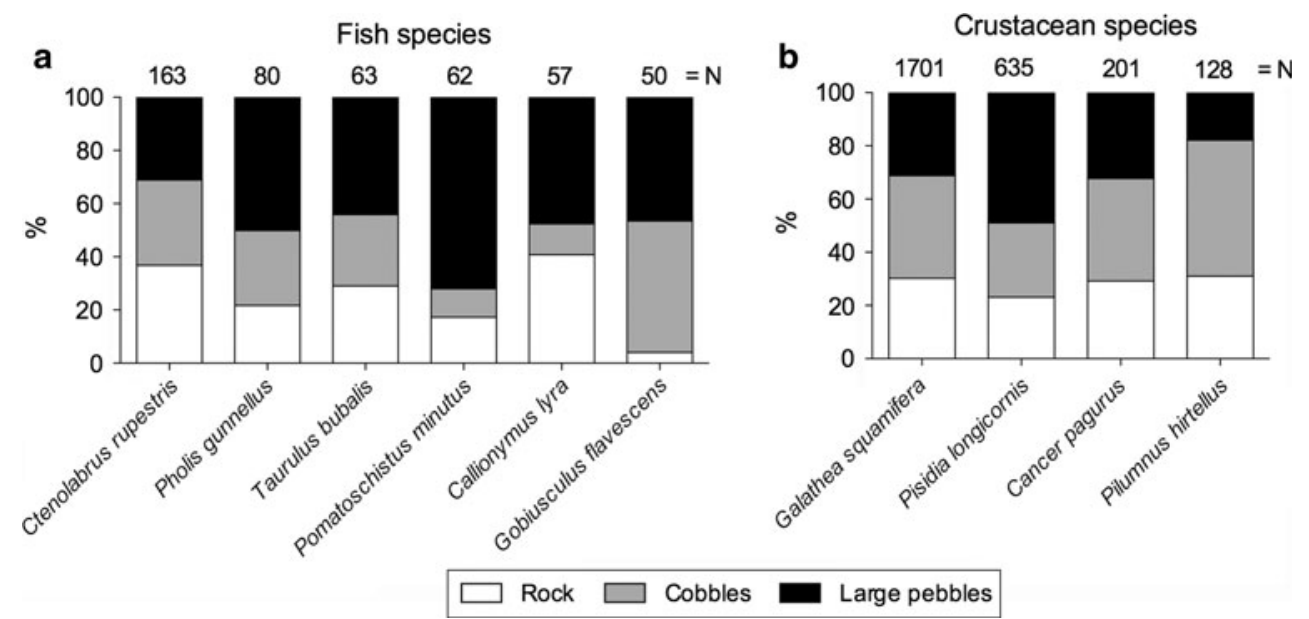

\section{Additional fish species}

Besides the species described above, six other species that were less abundant were observed in the area. These species were Spinachia spinachia ( $n=2$ over the entire sampling period), Ciliata mustela $(n=1)$, Entelurus aequoreus $(n=1)$, Myoxocephalus scorpius $(n=4)$, Liparis spp. ( $n=13)$ and Zoarces viviparus $(n=14)$. Because these species were only sighted occasionally, it was not possible to establish a reliable species-substratum association.

\section{Galathea squamifera}

The squat lobster (G. squamifera) was by far the most abundant crustacean species, with an average of 5.2 ind. $\mathrm{m}^{-2}$ (SD 2.3), and was more or less equally distributed over all of the substrata, with $30 \%$ of the sightings in rock, $39 \%$ in cobbles and $31 \%$ in large pebbles (Fig. 5b). G. squamifera was observed in all of the months but showed a slight seasonality, with the highest occurrence in September (Fig. 6b).

\section{Pisidia longicornis}

With an average abundance of 1.9 ind. $\mathrm{m}^{-2}$ (SD 1.1), the longclawed porcelain crab (P. longicornis) was the second most abundant crustacean species (Fig. 5b) and $49 \%$ of the members of this species were observed in the category large pebbles. This species was also sighted in the category rock ( $23 \%$ of the sightings) and in cobbles ( $28 \%$; Fig. 5b). Like the squat lobster, this species was most abundant in September, followed by August and July. In June, only a few members of this species were found (Fig. 6b).

\section{Cancer pagurus}

The edible crab (C. pagurus) was the third most abundant crustacean species, with an average abundance of 0.6 ind. $\mathrm{m}^{-2}$ (SD 0.1). Similar to the squat lobster (G. squamifera), the edible crab was found equally distributed in the substrata of cobbles (39\%), rock (29\%) and large pebbles (32\%; Fig. 5b). C. pagurus was observed in all of the months, with slightly higher abundances in August and September compared with June and July (Fig. 6b).

\section{Pilumnus hirtellus}

The hairy crab ( $P$. hirtellus) was found in an average abundance of 0.4 ind. $\mathrm{m}^{-2}$ (SD 0.1) and showed the strongest substratum affinity, with $51 \%$ of the individuals found in the cobble substratum followed by the rock category (31\%; Fig. 5b). The substrate large pebbles contained only $18 \%$ of the observed members of this comparatively small species. The presence in the category cobbles was obvious in all of the months, except for September, when the hairy crab was mostly seen in the substratum rock (Fig. 6b). P. hirtellus showed no clear seasonality but was mainly seen in September, followed by July.

\section{Additional crustacean species}

In addition to the four decapod species described above, the following crustaceans were observed in lower numbers over the sampling period: Necora puber $(n=17)$, Liocarcinus spp. $(n=12)$, Pagurus spp. $(n=8)$, Carcinus maenas $(n=4)$ and Homarus gammarus $(n=2)$. Because these species were sighted only occasionally, it was not possible to establish a reliable species-substratum association.

\section{Discussion}

Different authors have stressed that standard visual sampling is not adequate to identify and accurately census cryptobenthic fish and crustaceans because this method 
Fig. 6 Relative abundances for the six most abundant fish species (a) and the four most abundant crustacean species

(b) in the three substrate categories over the whole sampling time. Additionally, the ordinal-scaled densities of the brown and red algae are given as present (+) or absent (o) for red algae and the density of Laminaria for every month in the substrate categories as "dense" (20-50 Laminaria $\left.\mathrm{m}^{-2}\right)$ or "sparse" $(0-5$ Laminaria $\left.\mathrm{m}^{-2}\right)$. The category "present" (5-20 Laminaria $\mathrm{m}^{-2}$ ) was not found over the entire sampling period and was therefore excluded in the legend of the graph a Ctenolabrus rupestris
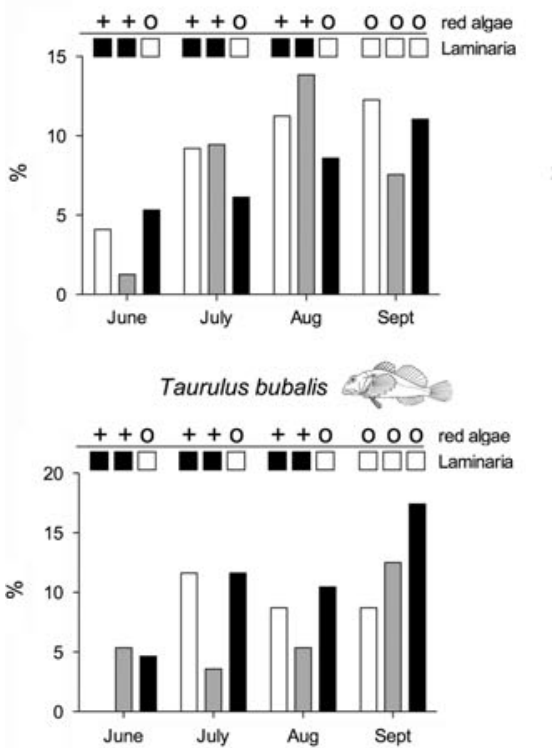

Callionymus lyra ese
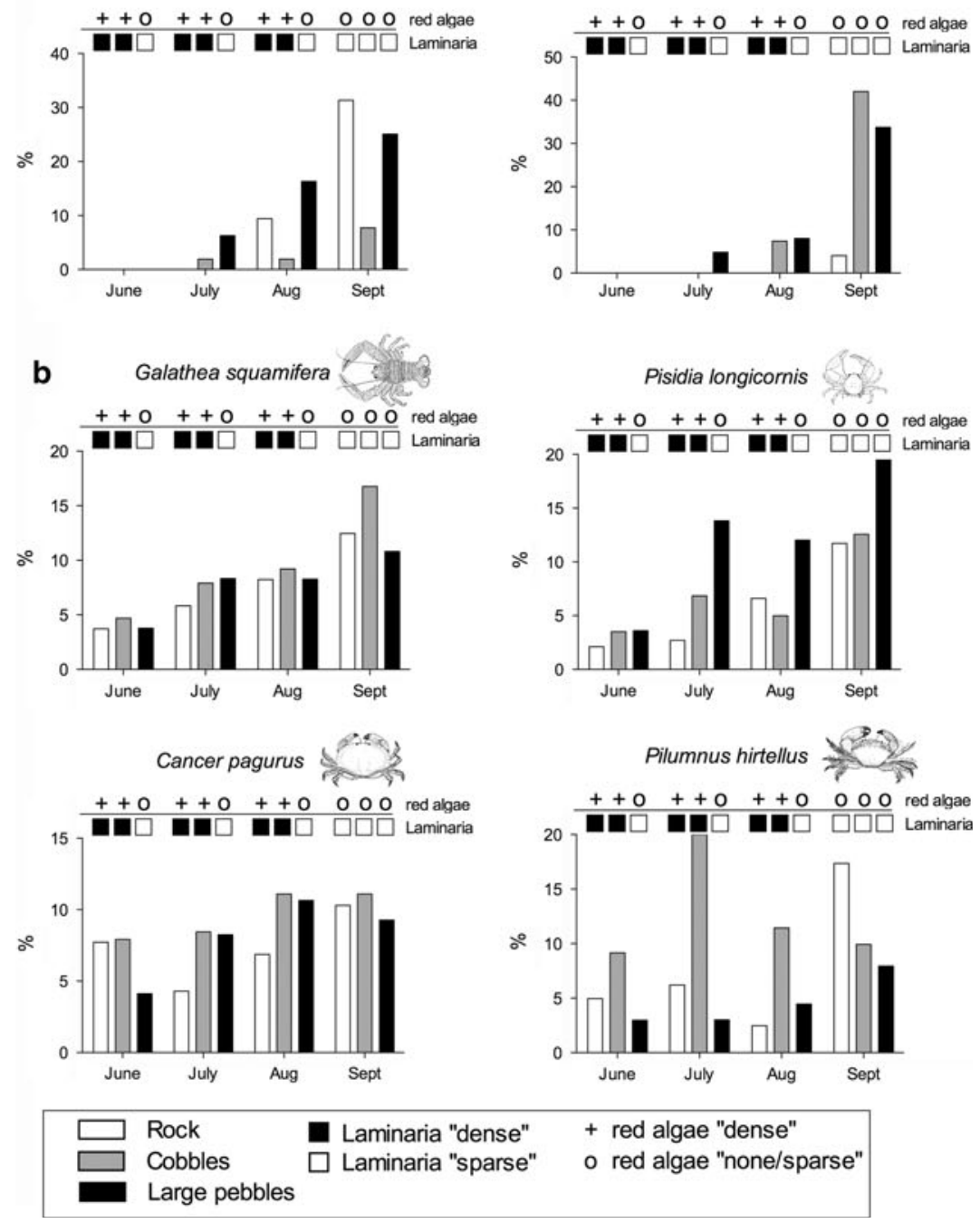

Pholis gunnellus e...……

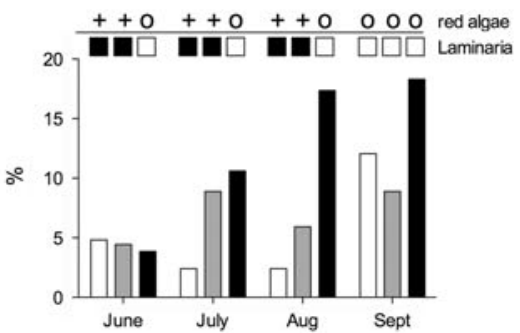

Pomatoschistus minutus

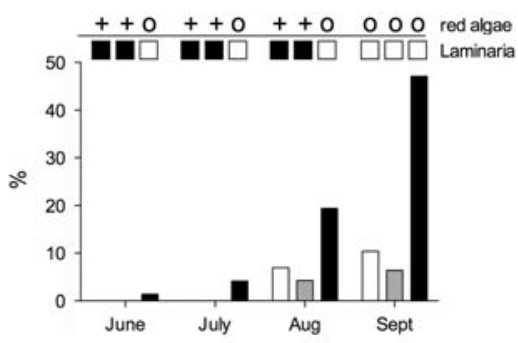

Gobiusculus flavescens 2

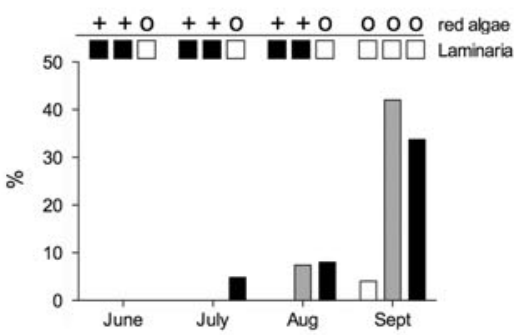

Pisidia longicornis

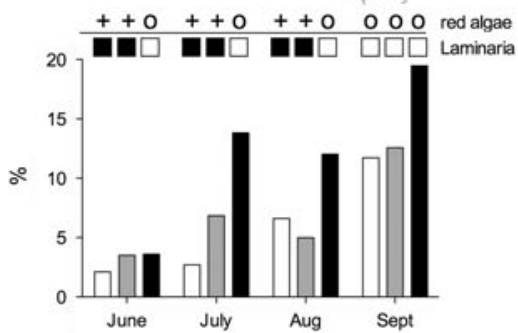

Aug Sept 
frequently leads to an underestimation of the number of individuals and species (Willis 2001; La Mesa et al. 2006). We agree with this hypothesis when visual sampling only includes swimming above the substrate over transects. Similar to Beldade and Goncalves (2007), we therefore strongly recommend to invest in dive time and to carefully turn individual stones, especially for micro-scale assessments of small-scale substratum characteristics with regard to the associated cryptobenthic well-camouflaged assemblage. Using this method, hidden species between and under stones can be often identified, generating a precision in species-habitat assessments that are often not achievable even with retrospective underwater photography or video documentation of a certain area (Ehrenberg and Ejdung 2008). Another method to increase the efficiency of fish counting is the use of anaesthetics (Sayer et al. 1994). Because the application of anaesthetics to relatively flat areas with some stone coverage is technically problematic, has an unknown impact on the community and does not provide significantly better results than a thorough linetransect count that includes turning stones (Beldade and Goncalves 2007), we selected the latter method as most suitable for our repetitive fish and decapod crustacean assessment.

However, it has to be noted that this method still provides an underestimation, especially of smaller crustaceans, such as Pilumnus hirtellus and Pisidia longicornis, because they are highly camouflaged under stones and in niches and do vanish quickly when disturbed by the observer. Furthermore, other species, such as hermit crabs, are difficult to detect, and highly mobile swimming crabs could escape before being detected by the observer. Therefore, we assume that these species were probably more abundant than represented in our study area. The species may form an unknown part of a hidden community that is only detectable using additional destructive sampling methods, such as the random use of suction samplers (Robinson and Tully 2000; Pallas et al. 2006).

Letourneur et al. (2003) and Moore et al. (2010) stated that individual environmental and biological factors on a fine scale are most important for driving the distribution and abundance of a fish assemblage and that broad-scale habitat definitions are often not able to give precise information about the assemblage structure and occurrence of species. Our study clearly supports these findings and provides evidence that the composition of the fish assemblage in the sublittoral hard-bottom kelp forests of Helgoland depends on much finer classifications than "hard bottom" or "kelp forest". Only three out of a total of 12 species occurred in high abundances in the area over the entire sampling period (Ctenolabrus rupestris, Pholis gunnelus and Taurulus bubalis), whereas the other species either occurred as temporally restricted (Callionymus lyra,
Gobiusculus flavescens and Pomatoschistus minutes) or occurred in very low numbers. However, all of the strictly benthic fish species, which occurred in high abundances so that an association with a certain habitat type was possible, revealed a distinct association with one of the three substratum categories. A similar dominance feature is common to many inshore and shallow rocky shore communities, with few species forming the largest part of the community (Magill and Sayer 2002; La Mesa et al. 2006; Wilhelmsson et al. 2006). For the crustaceans, the spatial distribution was not as distinct as for the fish. However, four species still dominated the crustacean community, and one of the species (Galathea squamifera) was significantly more abundant than the other three species ( $P$. longicornis, Cancer pagurus and P. hirtellus).

When analysing the functional relationships between species and their habitats, a distinct knowledge about the specific habitat requirements of a species is necessary (Gotceitas et al. 1995; Fraser et al. 1996; Letourneur et al. 2003; Chatfield et al. 2010). Our study indicates that the strength of the association of a certain fish species with a certain kind of substratum and therefore also the probability of the occurrence of a certain fish species or age class in a certain area is basically structured hierarchically with three levels: the general lifestyle of the fish species (e.g. benthic or semi-pelagic), the availability of an adequately sized shelter with respect to the size of the fish in a very narrow size scale and finally the colouration of the substrate, which must suit the camouflage colour of the fish.

Therefore, we follow La Mesa et al. (2006) who stated that, especially for cryptobenthic fish assemblages, habitat use can only be investigated on small mosaic-like scales. In addition to this, we suggest that the size of the target fish species should be used as a reference in order to determine the dimensions of the optimal sampling scale.

Interestingly, the most abundant species in our study, the suprabenthic goldsinny (C. rupestris), did not show a distinct substratum association. Sayer et al. (1993) suggest that the availability of the preferred refuge type is essential to determining goldsinny presence and report that water depths, macro-algal cover and high current speeds did not affect adult goldsinny distribution when suitable refuges were present. In their study, refuges consisted predominantly of spaces between or under rocks and boulders with multiple narrow entrances. This refuge type was often found in our study area, mainly in the natural categories rock and sometimes cobbles. In contrast, in our study, the goldsinnies were similarly abundant throughout all of the three natural categories, including the category large pebbles, a substratum type that is not typically associated with goldsinnies because hiding places are rare in this category. Hillden (1981) reported that $C$. rupestris, although strongly territorial, leaves its refuge for short excursions normally of 
less than a minute if, for example, an attractive food source is available outside. This behaviour possibly biased our results for the goldsinnies by attracting them to less suitable substratum types because the diver had turned a stone and therefore uncovered small crustaceans serving as an unexpected additional food source.

Another remarkable finding was that the young-of-theyear (age class $0+$ ) goldsinnies did not show a distinct substratum association. The spawning season of $C$. rupestris in the study area is in May and June (Hillden 1981; Krüß 1988). This result is consistent with the sightings of pregnant goldsinnies between June and July and the occurrence of $0+$ individuals in July and August, reaching a size (total length) of $2-3 \mathrm{~cm}$ (sometimes up to $5 \mathrm{~cm}$ ) in September. These juveniles showed no clear association for any of the three natural substrata (pers. observation) but were mostly detected after turning stones and sometimes in combination with bushy red algae. Sayer et al. (1993) found no significant combination between algal cover and $0+$ goldsinnies but also observed some individuals in or around macro-algae.

For the crustaceans, we found the smaller species $P$. longicornis and P. hirtellus mainly between and under stones in the categories large pebbles or cobbles. The larger species $C$. pagurus and G. squamifera, in contrast, were observed in similar distributions over all of the substratum categories and in all of the size classes. Therefore, we assume that the use of a certain substratum may depend on the size of the individual itself and its mobility. For example, C. pagurus is a highly mobile species, and larger individuals were counted when they were moving above the substrate, whereas smaller individuals were generally hidden under stones or buried in the sediment. Silva et al. (2010) found that larger individuals of $C$. pagurus, for example, migrate during high water to the intertidal zone to feed. It is possible that the abundance of prey organisms is more important than the availability of refuges for this robust and dominant species.

Larger G. squamifera were mostly found between niches and cavities of larger stones, whereas smaller individuals were hidden under pebbles or in small holes. These results are in accord with the study of Pallas et al. (2006), who found that some larger decapod invertebrates modified their habitat preference during their life cycle to minimise the trade-off among different stress factors. For other species, like P. longicornis and Pilumnus spp., the authors found no spatial segregation between juvenile and adult phases.

In addition to the substratum characteristics, the macroalgal coverage in the area was also assessed. We postulate that we did not miss a significant number of individuals, except perhaps some juveniles when counting between the Laminaria, because most benthic fish do not flee, and the suprabenthic goldsinny showed a distinct inquisitive behaviour and even came nearby when the diver started to turn stones. Some decapod crustacean species were detected in other studies between the holdfasts of Laminaria hyperborea, such as $P$. hirtellus, $P$. longicornis, $G$. squamifera and juvenile $C$. pagurus, but only in lower numbers, and these species do not form a large part of the associated Laminaria community (Schultze et al. 1990; Christie et al. 2003).

In general, many fish species seem to be associated with macro-algal vegetation (Schultze et al. 1990; Anderson and Underwood 1994; Pihl et al. 1994; Norderhaug et al. 2007; Chatfield et al. 2010). Pihl et al. (1994) found positive correlations between the fish biomass and total vegetation biomass in rocky-bottom habitats on the Swedish west coast but also found a negative impact on the fish diversity when the proportion of filamentous algae (mainly green algae) was high. The authors suggest that the change in the physical complexity of the vegetation cover is not ideal for some foraging species. La Mesa et al. (2006) found significant species-substratum (rock, stones or plateau) relationships on a small and intermediate scale $(2 \times 5 \mathrm{~m})$, but at the level of microhabitat (a $30 \times 30 \mathrm{~cm}$ area centred on the fish), the authors suggest that the investigated species were almost completely dependent on whether the substrate was either vegetated or composed of bare rock. Similarly, Chatfield et al. (2010) also found that although the substrate type was the most influential variable for species distribution, the depth and macro-algal type also influenced the occurrence of species over the correlating substrate types. Epiphytes can provide refuge for fish and crustaceans against predation and can also offer a variety of prey organisms for fish and crabs (Christie et al. 2003; Norderhaug et al. 2005). For example, kelp forests serve as heterogeneous habitat for a variety of species (Schultze et al. 1990; Christie et al. 2003; Norderhaug et al. 2007). However, in our study, both the fish and decapod crustaceans were negatively correlated with the kelp coverage, and most of the fish were counted in the substratum large pebbles, where no or only sparse growth of Laminaria hyperborea as well as bushy red algae was observed. A similar finding was also reported by Wilhelmsson et al. (2006), who found no correlation between main cold-water fish species, such as the goldsinny, and algae cover but did find a positive correlation between fish occurrence and the availability of suitable habitat features in the form of hiding places. Furthermore, some studies also suggest that some species do not prefer dense stands of submerged aquatic vegetation per se because of a reduced detection distance of approaching predators or a reduced foraging ability (Gorman et al. 2009; Thistle et al. 2010; Smith et al. 2011). Submerged aquatic vegetation areas may therefore serve more as a temporal refuge in case of a real predation 
risk or to temporally exploit the invertebrate food source (Norderhaug et al. 2005) that is often found between structurally complex holdfasts, for example, those of kelp.

In addition to substratum type and macro-algal coverage, the temperature and life cycles also had an impact on the fish and crustacean abundance over the study time, with a peak in September in the overall abundance and species richness. Similar to other factors, including periodic changes in salinity or nutrients over time, temperature is assumed to have a temporally intermediate- or longer-scale influence on the overall abundance but less influence on the small-scale distribution within substratum types. However, an interesting factor is the time of the day and the tides, which act within smaller temporal scales instead of spatial scales. Because tides may significantly affect the habitat quality because of the energetic cost to an organism to maintain its position, and the time of the day and illumination may significantly affect the availability of prey and the presence of potential predators (Magill and Sayer 2002; Bell and Turner 2003; Silva et al. 2010), these variables may significantly affect the results. However, because these variables interact strongly and may confound each other, separate studies with a carefully planned experimental design are necessary to discriminate among these variables.

This study was done in the only existing natural hardbottom area of the southern North Sea where fishing activity in general is just a minor influence. Towed fishing is forbidden and furthermore not practicable because of the existing kelp density and stony substratum. Therefore, the results of this study can be transferred for similar hardbottom areas, which occurs, for example, in Britain or Norway but not for the southern North Sea in general which is dominated by soft and sandy substratum and highly disturbed by fishing activity.

\section{Conclusion}

Our study revealed strong species-substratum relationships in the subtidal benthic fish community off Helgoland, in the southern North Sea, on a micro-scale level. In contrast, no distinct relationships were found for the decapod crustaceans. In both of the assemblages, a single species dominated the community in terms of abundance, whereas the other species occurred in lower abundances, were temporarily restricted or were only occasionally seen over the entire sampling period; especially for the benthic fish, we hypothesised that habitat selection is based on a threelevel hierarchical system, with the general lifestyle of the species (benthic or semi-pelagic) forming the first level, the availability of an adequately sized shelter with respect to the size of the fish in a very narrow size scale forming the second level and the colouration of the substratum with respect to the camouflage colour of the fish as the third level.

Based on the results of this study, we postulate that diver-supported assessment methods are adequate for micro-scale fish-habitat studies in shallow-water areas. Because of the distinct size dependency of the fish and crustaceans, however, we recommend for future studies to discriminate among different age or size classes within the species. This specificity would facilitate an even more accurate analysis, allowing deeper insight into the functional relationship between species and their habitat and leading to a better understanding of why fish settle during a certain time at a certain place.

Acknowledgments We thank the numerous divers and dive mission leaders, especially Matthias Wehkamp, of the Alfred Wegener Institute for their help in the field even under harsh and cold conditions. Furthermore, we want to thank Andrea Schlunk for language assistance as well as two unknown reviewers for their helpful comments in preparing the manuscript. This manuscript was done associated with the project COSYNA (Coastal Observation System for Northern and Arctic Seas; www.cosyna.org).

\section{References}

Anderson MJ, Millar RB (2004) Spatial variation and effects of habitat on temperate reef fish assemblages in northeastern New Zealand. J Exp Mar Biol Ecol 305(2):191-221. doi:10.1016/ j.jembe.2003.12.011

Anderson MJ, Underwood AJ (1994) Effects of substratum on the recruitment and development of an intertidal estuarine fouling assemblage. J Exp Mar Biol Ecol 184(2):217-236

Beldade R, Goncalves EJ (2007) An interference visual census technique applied to cryptobenthic fish assemblages. Vie Milieu 57(1-2):65-69

Bell JJ, Turner JR (2003) Temporal and spatial variability of mobile fauna on a submarine cliff and boulder scree complex: a community in flux. Hydrobiology 503(1-3):171-182

Chatfield BS, Van Niel KP, Kendrick GA, Harvey ES (2010) Combining environmental gradients to explain and predict the structure of demersal fish distributions. J Biogeogr 37(4):593605. doi:10.1111/j.1365-2699.2009.02246.x

Christie H, Jorgensen NM, Norderhaug KM, Waage-Nielsen E (2003) Species distribution and habitat exploitation of fauna associated with kelp (Laminaria hyperborea) along the Norwegian coast. J Mar Biol Assoc UK 83(4):687-699. doi:10.1017/S0025315403 007653h

Damalas D, Maravelias CD, Katsanevakis S, Karageorgis AR, Papaconstantinou C (2010) Seasonal abundance of non-commercial demersal fish in the eastern Mediterranean Sea in relation to hydrographic and sediment characteristics. Estuar Coast Shelf Sci 89(1):107-118. doi:10.1016/j.ecss.2010.06.002

De Kluijver MJ (1989) Sublittoral hard substrate communities of the Southern Delta area, SW Netherlands. Bijdr Dierkd 59(3):141-158

De Kluijver MJ (1991) Sublittoral hard substrate communities off Helgoland Helgol Meeresunters. Helgoland Mar Res 45(3):317-344

Ehrenberg SZ, Ejdung G (2008) Daily activity pattern of the sand goby, Pomatoschistus minutus (Pisces), at low light intensity. Hydrobiol 603:129-137. doi:10.1007/s10750-007-9253-4 
Fischer P, Eckmann R (1997a) Seasonal changes in fish abundance, biomass and species richness in the littoral zone of a large European lake, Lake Constance, Germany. Arch Hydrobiol 139(4):433-448

Fischer P, Eckmann R (1997b) Spatial distribution of littoral fish species in a large European lake, Lake Constance, Germany. Arch Hydrobiol 140(1):91-116

Fischer P, Weber A, Heine G, Weber H (2007) Habitat structure and fish: assessing the role of habitat complexity for fish using a small, semiportable, 3-D underwater observatory. Limnol Oceanogr Methods 5:250-262

Franke HD, Gutow L (2004) Long-term changes in the macrozoobenthos around the rocky island of Helgoland (German Bight, North Sea). Helgol Mar Res 58(4):303-310. doi:10.1007/ s10152-004-0193-3

Fraschetti S, Terlizzi A, Benedetti-Cecchi L (2005) Patterns of distribution of marine assemblages from rocky shores: evidence of relevant scales of variation. Mar Ecol Prog Ser 296:13-29

Fraser S, Gotceitas V, Brown JA (1996) Interactions between ageclasses of Atlantic cod and their distribution among bottom substrates. Can J Fish Aquat Sci 53(2):305-314

Garcia-Charton JA, Ruzafa AP (1998) Correlation between habitat structure and a rocky reef fish assemblage in the southwest Mediterranean. Mar Ecol PSZNI 19(2):111-128

Gorman AM, Gregory RS, Schneider DC (2009) Eelgrass patch size and proximity to the patch edge affect predation risk of recently settled age 0 cod (Gadus). J Exp Mar Biol Ecol 371(1):1-9. doi:10.1016/j.jembe.2008.12.008

Gotceitas V, Fraser S, Brown JA (1995) Habitat use by juvenile Atlantic Cod (Gadus-Morhua) in the presence of an actively foraging and non-foraging predator. Mar Biol 123(3):421-430

Harms J (1993) Check list of species (algae, invertebrates and vertebrates) found in the vicinity of the island of Helgoland (North-Sea, German Bight)—a review of recent records. Helgol Meeresunters 47(1):1-34

Hillden NO (1981) Territoriality and reproductive behaviour in the Goldsinny, Ctenolabrus rupestris L. Behav Process 6(3):207-221

Hunter WR, Sayer MDJ (2009) The comparative effects of habitat complexity on faunal assemblages of northern temperate artificial and natural reefs. ICES J Mar Sci 66(4):691-698. doi:10.1093/icesjms/fsp058

Jackson EL, Attrill MJ, Jones MB (2006) Habitat characteristics and spatial arrangement affecting the diversity of fish and decapod assemblages of seagrass (Zostera marina) beds around the coast of Jersey (English Channel). Estuar Coast Shelf Sci 68(3-4): 421-432. doi:10.1016/j.ecss.2006.01.024

Krüß A (1988) Die benthische Fischfauna des Helgoländer Felssockels. Diploma thesis, University of Karlsruhe

La Mesa G, Di Muccio S, Vacchi M (2006) Structure of a Mediterranean cryptobenthic fish community and its relationships with habitat characteristics. Mar Biol 149(2):149-167. doi:10.1007/s00227-005-0194-z

La Mesa G, Molinari A, Gambaccini S, Tunesi L (2011) Spatial pattern of coastal fish assemblages in different habitats in Northwestern Mediterranean. Mar Ecol 32(1):104-114. doi:10.1111/ j.1439-0485.2010.00404.x

Letourneur Y, Ruitton S, Sartoretto S (2003) Environmental and benthic habitat factors structuring the spatial distribution of a summer infralittoral fish assemblage in the north-western Mediterranean Sea. J Mar Biol Assoc UK 83(1):193-204

Lüning K (1970) Diving investigations on the vertical distribution of sublittoral algal vegetation near Helgoland Helgol Wiss Meeresunters 21(3):197-212

Magill SH, Sayer MDJ (2002) Seasonal and interannual variation in fish assemblages of northern temperate rocky subtidal habitats. J Fish Biol 61(5):1198-1216. doi:10.1006/jfbi.2002.2134
Moore CH, Harvey ES, Van Niel K (2010) The application of predicted habitat models to investigate the spatial ecology of demersal fish assemblages. Mar Biol 157(12):2717-2729. doi:10.1007/s00227-010-1531-4

Morton JK, Gladstone W (2011) Spatial, temporal and ontogenetic variation in the association of fishes (family Labridae) with rocky-reef habitats. Mar Freshw Res 62(7):870-884. doi:10.1071/ $\operatorname{mf} 10315$

Norderhaug KN, Christie H, Fossa JH, Fredriksen S (2005) Fishmacrofauna interactions in a kelp (Laminaria hyperborea) forest. J Mar Biol Assoc UK 85(5):1279-1286. doi:10.1017/s0025315 405012439

Norderhaug KM, Christie H, Fredriksen S (2007) Is habitat size an important factor for faunal abundances on kelp (Laminaria hyperborea)? J Sea Res 58(2):120-124. doi:10.1016/j.seares. 2007.03.001

Pallas A, Garcia-Calvo B, Corgos A, Bernardez C, Freire J (2006) Distribution and habitat use patterns of benthic decapod crustaceans in shallow waters: a comparative approach. Mar Ecol Prog Ser 324:173-184. doi:10.3354/meps324173

Pardo LM, Palma AT, Prieto C, Sepulveda P, Valdivia I, Ojeda FP (2007) Processes regulating early post-settlement habitat use in a subtidal assemblage of brachyuran decapods. J Exp Mar Biol Ecol 344(1):10-22. doi:10.1016/j.jembe.2006.12.024

Pihl L, Wennhage H, Nilsson S (1994) Fish assemblage structure in relation to macrophytes and filamentous epiphytes in shallow non-tidal rocky-bottom and soft bottom habitats. Environ Biol Fish 39(3):271-288. doi:10.1007/bf00005129

Reicherti K, Buchholz F, Bartsch I, Kersten T, Gimenez L (2008) Scale-dependent patterns of variability in species assemblages of the rocky intertidal at Helgoland (German Bight, North Sea). J Mar Biol Assoc UK 88(7):1319-1329. doi:10.1017/s0025315 408001926

Robinson M, Tully O (2000) Spatial variability in decapod community structure and recruitment in sub-tidal habitats. Mar Ecol Prog Ser 194:133-141. doi:10.3354/meps194133

Sayer MDJ, Poonian C (2007) The influence of census technique on estimating indices of macrofaunal population density in the temperate rocky subtidal zone. Under Technol 27(3):119-139

Sayer MDJ, Gibson RN, Atkinson RJA (1993) Distribution and density of populations of goldsinny wrasse (Ctenolabrus rupestris) on the west coast of Scotland. J Fish Biol 43:157-167

Sayer MDJ, Cameron KS, Wilkinson G (1994) Fish species found in the rocky sublittoral during winter months as revealed by the underwater application of the anaesthetic quinaldine. J Fish Biol 44(2):351-353

Scharf FS, Manderson JP, Fabrizio MC (2006) The effects of seafloor habitat complexity on survival of juvenile fishes: species-specific interactions with structural refuge. J Exp Mar Biol Ecol 335(2):167-176. doi:10.1016/j.jembe.2006.03.018

Schultze K, Janke K, Kruss A, Weidemann W (1990) The macrofauna and macroflora associated with Laminaria digitata and L. hyperborea at the island of Helgoland (German Bight, North Sea) Helgol Meeresunters 44(1):39-51

Silva ACF, Hawkins SJ, Boaventura DM, Brewster E, Thompson RC (2010) Use of the intertidal zone by mobile predators: influence of wave exposure, tidal phase and elevation on abundance and diet. Mar Ecol Prog Ser 406:197-210. doi:10.3354/meps08543

Simoes N, Apel M, Jones DA (2001) Intertidal habitats and decapod faunal assemblages (Crustacea: Decapoda) of Socotra Island, Republic of Yemen. Hydrobiology 449(1-3):81-97. doi:10.1023/ a: 1017541019388

Smith TM, Hindell JS, Jenkins GP, Connolly RM, Keough MJ (2011) Edge effects in patchy seagrass landscapes: the role of predation in determining fish distribution. J Exp Mar Biol Ecol 399(1):8-16. doi:10.1016/j.jembe.2011.01.010 
Stal J, Pihl L, Wennhage H (2007) Food utilisation by coastal fish assemblages in rocky and soft bottoms on the Swedish west coast: Inference for identification of essential fish habitats. Estuar Coast Shelf Sci 71(3-4):593-607. doi:10.1016/j.ecss.2006.09.008

Thistle ME, Schneider DC, Gregory RS, Wells NJ (2010) Fractal measures of habitat structure: maximum densities of juvenile cod occur at intermediate eelgrass complexity. Mar Ecol Prog Ser 405:39-56. doi:10.3354/meps08511

Underwood AJ, Chapman MG (1996) Scales of spatial patterns of distribution of intertidal invertebrates. Oecologia 107(2):212224. doi:10.1007/bf00327905

Wentworth H (1922) A scale of grade and class terms of clastic sediments. J Geol 30:377-392

Wheeler A (1978) Key of the fishes of Northern Europe. Frederick \& Warne Ltd, London
Wilhelmsson D, Yahya SAS, Ohman MC (2006) Effects of highrelief structures on cold temperate fish assemblages: a field experiment. Mar Biol Res 2(2):136-147. doi:10.1080/17451000 600684359

Willis TJ (2001) Visual census methods underestimate density and diversity of cryptic reef fishes. J Fish Biol 59(5):1408-1411

Wiltshire KH, Malzahn AM, Wirtz K, Greve W, Janisch S, Mangelsdorf P, Manly BFJ, Boersma M (2008) Resilience of North Sea phytoplankton spring bloom dynamics: an analysis of long-term data at Helgoland Roads. Limnol Oceanogr 53(4): 1294-1302

Wiltshire KH, Kraberg A, Bartsch I, Boersma M, Franke HD, Freund J, Gebuhr C, Gerdts G, Stockmann K, Wichels A (2010) Helgoland roads, North Sea: 45 years of change. Estuaries Coasts 33(2):295-310. doi:10.1007/s12237-009-9228-y 